\title{
PROCEDIMENTOS ESSENCIAIS DO PROCESSO DE COLONIZAÇÃO DAS PRÁTICAS COTIDIANAS DE CONSUMO PELO LUGAR DE PODER DA PRODUÇÃO
}

\author{
Essential procedures of the colonization of daily \\ consumption practices by the production place of power \\ Procedimientos esenciales de la colonización de las \\ prácticas de consumo de la vida cotidiana por el lugar de \\ poder de la producción
}

\author{
Isaac Matheus Santos Batista \\ Universidade Federal Rural de Pernambuco, Recife, Brasil. \\ Bacharel em Design pela Universidade Federal de Pernambuco e mestre em Consumo, Cotidiano e \\ Desenvolvimento Social pela Universidade Federal Rural de Pernambuco. \\ Email: isaacmsbatista@gmail.com
}

\section{Marcelo Machado Martins}

Universidade Federal de Pernambuco, Recife, Brasil.

Doutor em Semiótica e Linguística Geral pela Universidade de São Paulo. Professor do Núcleo de Design e Comunicação da Universidade Federal de Pernambuco.

Email: machadomartins@yahoo.com.br

\author{
Raquel de Aragão Uchôa Fernandes \\ Universidade Federal Rural de Pernambuco, Recife, Brasil. \\ Doutora em Ciências Sociais pela Universidade do Estado do Rio de Janeiro. Professora do \\ Departamento de Ciências Domésticas da Universidade Federal Rural de Pernambuco. \\ Email: aragaouchoa@hotmail.com
}

RESUMO Este artigo visa compreender os procedimentos inerentes ao processo de colonização das práticas de consumo cotidianas pelo lugar de poder da produção. Através de um estudo de caso sobre a maneira como a maison de alta-costura Dior, que ocupava lugar de poder dentro do sistema de moda, colonizou as práticas de consumo de vestuário dos jovens e da classe trabalhadora dos anos 1960, inspirando-se nos trajes surgidos entre eles para a concepção de novos produtos de luxo, percebemos que existem quatro procedimentos inerentes ao referido processo, são eles: reconfiguração, refuncionalização, ressignificação e eticalização.

PALAVRAS-CHAVE Cotidiano, Produção, Consumo.

ABSTRACT This study aims to understand the procedures inherent to the colonization process of daily consumption practices by the production place of power. Through a case study on how the House of Dior, which was in the place of power of the fashion system, colonized the garment consumption practices of the young and the working class from the 1960s, drawing inspiration from the costumes emerged among them for the design 
of new luxury products, we realized that there are four procedures inherent to this process, which are: reconfiguration, refunctionalization, resignification and ethicalization. KEYWORDS Daily life, Production, Consumption.

RESUMEN Este estudio pretende comprender los procedimientos inherentes al proceso de colonización de las prácticas de consumo cotidianas por el lugar de poder de la producción. A través de un estudio de caso sobre cómo la maison de alta costura Dior, que estaba en el lugar del poder del sistema de moda, colonizó las prácticas de consumo de vestuario de los jóvenes y de la clase trabajadora de la década de 1960, inspirándose en los trajes que les surgieron para el diseño de nuevos productos de lujo, concebimos que hay cuatro procedimientos inherentes a este proceso, que son: reconfiguración, refunccionalización, resignificación y eticalización.

PALABRAS CLAVE Cotidiano, Producción, Consumo.

\section{INTRODUÇÃO}

O fazer científico começa muito antes de o pesquisador se colocar em frente a um computador ou se debruçar sobre seu papel com uma caneta em mãos. As experiências vividas pelo autor ou autora influenciam o percurso que ele ou ela faz até chegar ao resultado final de seu trabalho. A pesquisa que aqui se apresenta não foge à regra. Duas situações foram essenciais para os insights que deram origem a este artigo. A primeira foi a leitura do livro de Certeau (1998) intitulado A invenção do cotidiano, no qual há um capítulo em que ele discute as estratégias da produção e as táticas dos consumidores no cotidiano, mencionando que por vezes as práticas cotidianas podem ser colonizadas pelo lugar de poder da produção que as transforma em tecnologias para o exercício desse poder. A segunda situação foi a percepção do modo como pessoas do movimento da negritude e do movimento feminista começaram a protestar contra a incorporação de seu discurso e símbolos pela indústria da moda e pela cultura pop, de maneira que podíamos ver acontecer com nossos próprios olhos, em tempo real, o fenômeno da colonização das práticas cotidianas conforme Certeau (1998).

Entretanto, a segunda situação nos levou a perceber que o processo pelo qual passa a prática cotidiana ao ser colonizada pelo lugar de poder não é livre de tensões que, acreditamos, estimulam esses atos de resistência. O movimento da negritude, por exemplo, clama contra uma suposta apropriação cultural por parte da indústria da moda, acreditando que esta não compreende os significados dos adereços e roupas dos quais se apropria. Por outro lado, algumas feministas afirmam ocorrer uma banalização dos discursos do movimento quando estes vão para a indústria cultural, servindo para criar as representações de celebridadesmercadorias que cada vez mais se afirmam como feministas. Diante disso, ficou claro que a contribuição de Certeau (1998) acerca da colonização das práticas cotidianas precisava ser avançada, pois, apesar de explicitar que ela existe, ele não discorre acerca do que está implicado no processo de colonização efetuado pela produção.

A partir desse raciocínio, estabelecemos como objetivo do nosso estudo compreender os procedimentos inerentes ao processo de colonização das práticas de consumo cotidianas pelo lugar de poder da produção.

Conforme Daniel Miller (2007), muitas pesquisas no campo do consumo comumente analisam a produção e o consumo separadamente. Segundo o autor, 
fundamentalmente há uma falha na educação se continuarmos a viver em um mundo no qual [...] não consigamos ver os padrões de trabalho e relações sociais que, conexão após conexão, seguem os vários eventos através dos quais os bens criam esta corrente entre produção e consumo. (MILLER, 2007, p. 52)

Visto tal necessidade de analisar o diálogo entre esses dois âmbitos, acreditamos que os resultados da nossa pesquisa poderão ser relevantes para a compreensão da relação entre produção e consumo, embora não esgotem esse assunto.

\section{METODOLOGIA}

Este estudo é de cunho qualitativo, pois sua preocupação principal é entender os sentidos do fenômeno observado, sem se deter em suas características numericamente mensuráveis (MARCONI; LAKATOS, 2010).

Para atingir nosso objetivo, fizemos um estudo de caso (Ibidem) analisando o modo como a marca de luxo Dior, nascida em 1946 como uma maison de alta-costura - título que a colocava num lugar de poder dentro do sistema de moda - incorporou aos seus produtos determinadas formas de vestir que surgiram no cotidiano dos jovens da década de 1960. Para esta análise, as técnicas de pesquisa empregadas foram a pesquisa bibliográfica, por meio de fontes secundárias já publicadas, provenientes de diversos formatos, e a pesquisa documental, que se deu através de fontes primárias como fotografias e filmes (Ibidem).

As fotos e o filme compõem uma amostragem intencional, pois, conforme Marconi e Lakatos (2010), foram escolhidos na expectativa de contribuir com dados relevantes para nossa pesquisa. Apesar de as fotos terem sido feitas em Nova York, já nos anos 2000, pelo Metropolitan Museum of Art, e o filme ter sido gravado na Inglaterra, o que nos interessa é o fato de esses documentos apresentarem peças de vestuário de altacostura da maison Dior que foram criadas nos anos 1960 na França. A escolha por esse corpus se deu pois é nesse período que surge uma moda de rua entre os jovens europeus que vai ser colonizada pela Dior em seus produtos e comunicações de luxo.

Para analisar os vestuários, utilizamos os critérios de análise de imagem de moda definidos por Maciel e Miranda (2009), ao dissecarmos o traje de acordo com: forma; cor; material; composição das peças em si mesmas, entre si e sobre o corpo; e o gestual da pessoa que porta a roupa ou o acessório. Durante a análise, comparamos as características estéticas, simbólicas e práticas das roupas das imagens com o vestuário surgido entre os jovens nos anos 1960, pensando essa relação de maneira vinculada à história da marca em questão e da moda de forma geral.

Os resultados conseguidos através deste estudo foram abstraídos de modo que pudéssemos chegar aos procedimentos essenciais ocorridos no processo de colonização das práticas cotidianas pela produção e, assim, identificar categorias que pudessem ser aplicadas a outros contextos que não apenas ao vestuário de moda.

\section{ESTRATÉGIAS E TÁTICAS NA RELAÇÃO PRODUÇÃO-CONSUMO}

Uma das principais perspectivas teóricas sobre o consumo e a sociedade de consumo trata da produção do consumo. De acordo com 
esse pensamento, que remonta à economia clássica, o fim da produção seria o consumo, meio pelo qual as pessoas satisfazem suas necessidades e desejos através da compra e uso de mercadorias. Como no começo do século XX os níveis de produção se elevavam cada vez mais com o sistema de gestão e produção em massa pensado por Henry Ford, a produção precisava criar mercados consumidores e educá-los, dirigindo e manipulando seu desejo por adquirir e usufruir de novos bens de consumo, através da publicidade e dos diversos meios de comunicação de massa (FEATHERSTONE, 1995).

Essa perspectiva ainda afirma que no momento em que o consumo passa a ser conduzido pela produção, ele acaba tomando a forma racional da produção e passa a existir sob a mesma lógica da mercadoria. Seu aspecto qualitativo dá lugar ao quantitativo, o que geraria uma corrupção dos bons valores e da alta cultura, pois as massas manipuladas teriam seu modo de viver guiado pela produção e por sua lógica do valor de troca que forneceria uma cultura ${ }^{1}$ de menor qualidade para as pessoas. O esvaziamento do valor de uso da mercadoria permitiria que ela fosse associada a qualquer outro valor de uso, de modo que a publicidade teria a responsabilidade de associar objetos triviais, como pastas de dente e fósforos, a um mundo de sonhos e felicidade, escondendo o fato de que as pessoas estão sendo manipuladas a consumir aqueles produtos apenas para gerar lucro às indústrias e dando a impressão de que o consumo desses objetos realmente está ligado a valores mais elevados, quando na verdade está reduzido à lógica dos ganhos (Ibidem).

Entretanto, Lipovetsky (2009) discorda dessa abordagem, ao mostrar que o gosto pelas mudanças (que exige o consumo perene de novos produtos) e pelo espetáculo estético que os bens proporcionam não é uma invenção do capitalismo e não nasceu nas indústrias ou na mente maléfica de um burguês gordo e bem-vestido, como querem muitas charges acerca do assunto, mas fazem parte do espírito da modernidade. Essa afirmação reitera as observações de Lefebvre (1991) quando diz que o espírito de mudança, que está no cerne do conceito de modernidade e é um dos pilares da moda, é usado pelo capitalismo para incitar a obsolescência das necessidades dos consumidores e, por conseguinte, gerar um sentimento de mal-estar que só pode ser estancado por meio da satisfação efêmera que o consumo propicia. Dessa forma, o capitalismo torna o cotidiano rentável, apropriando-se do desejo dos consumidores, ao revelar e orientar esse desejo por meio da produção, publicização e distribuição de novos bens de consumo.

Entretanto, se concluirmos nosso pensamento na noção de consumo dirigido pela produção, voltaremos ao estado inicial desse tópico, entendendo as práticas de consumo como mero reflexo da manipulação exercida pela produção que reduz essa relação ao valor de troca. Se é verdade que o sistema capitalista estimula novos desejos e necessidades nos consumidores, fornecendo prontamente o objeto certo para preencher o vazio que eles sentem, é certo também que às pessoas é reservada a liberdade de escolher comprar ou não os mais novos itens disseminados nos meios de comunicação ou presentes nas prateleiras das lojas, de usá-los de forma diferente da que é proposta pelos especialistas etc. O consumo é um ato criativo. Silverstone (1999, p. 85) confirma essa ideia ao apresentar o seguinte argumento:

1. Featherstone (1995) estava se baseando em alguns textos sobre indústria cultural, os quais tocavam também no ponto acerca da publicidade de objetos físicos. 
O consumo é um trabalho árduo. [...] É o trabalho que une indivíduos e coletividades, definido por - definindo e partilhando - gosto, status ou carência. Dos produtos homogeneizadores de Lévi-Strauss, Kangol e Sony derivam as particularidades do estilo; os momentos de moda e identidade fabricadas por grupos, jovens ou etnicamente diversos, cujo poder na economia formal e, por isso, cuja participação na sociedade global são limitados ou, exceto nesses momentos de criatividade marginal, quase inexistentes. $O$ consumo é uma maneira de mediar e moderar os horrores da padronização. E comprar é apenas o começo. Um estágio no ciclo de vida da mercadoria, mas um ciclo que não tem início nem fim: um jogo contínuo, constante de produtos e significados, deslocando reiterada, dialeticamente, a atenção para longe da dor da extração ou da manufatura e em direção do objeto, de sua imagem e de sua apropriação no uso.

Dessa forma, percebe-se que o consumo não pode ser explicado apenas como resultado da manipulação alienante feita pela produção sobre as pessoas. Certeau (1998) explica a relação entre produção e consumo ao comparar o segundo com a fala. A língua portuguesa, por exemplo, é um sistema de representação que todos nós brasileiros compartilhamos. Existem determinadas regras gramaticais que regem toda a produção de textos verbais, escritos ou pronunciados no nosso país. Entretanto, o modo como fazemos uso da língua portuguesa, como construímos nossa fala, difere em certa medida de região para região, de pessoa para pessoa, de contexto para contexto. Ele diz que assim como há estilos de escrever e falar, há também estilos de fazer as coisas no dia a dia. Essas "maneiras de fazer” correspondem a um segundo nível que está debaixo de um nível primeiro e superior, ou seja, sob uma ordem imposta, sendo que os dois níveis estão combinados no contexto onde as práticas cotidianas ocorrem.

Quando essa relação de diferentes níveis é trazida para o âmbito do consumo, o autor afirma que a produção, que está no primeiro nível, produz o que quer e coloca o resultado à disposição das pessoas, mas o modo como o uso dos produtos ocorre - uso este que está no nível inferior - nem sempre é como o produtor queria. O consumidor modifica o sistema dentro do próprio sistema (Ibidem).

Para explicar como agem produtor e consumidor, Certeau (1998) elabora os conceitos de "estratégia" e "tática”. A estratégia diz respeito às ações manipuladoras executadas por meio de um sujeito (pessoa ou não) isolado que está numa posição de poder (no nível superior). A estratégia exige a existência de um lugar próprio, de onde o Outro, a exterioridade, é regulado a partir de sistemas e discursos totalizantes.

Por outro lado, táticas seriam ações pensadas e executadas que são determinadas pela ausência de um lugar próprio. Diferentemente da estratégia, a tática não possui um lugar próprio de observação e manipulação. A tática é o Outro e, sendo o Outro, atua no espaço que lhe é imposto pelo poder do sujeito manipulador da estratégia. É debaixo do olhar desse sujeito e dentro de seu campo de batalha que a tática deve habilmente utilizar seu tempo nas ocasiões que se apresentam. Certeau (1998) afirma que as práticas cotidianas dos consumidores são do tipo tático.

O lugar remete a algo estático enquanto o tempo remete a algo dinâmico, pois sempre avança. O lugar é o institucionalizado, a regra, a lei, o local do produtor e do que foi produzido; o tempo, por sua vez, diz respeito ao desenrolar das práticas de consumo que acontecem dentro do espaço regrado pelo sujeito que está no lugar de poder, mas que têm um maior grau de variabilidade, dinamicidade, ajustamento e alteração. 
Desse ponto de vista, então, podemos compreender que no sistema de moda o poder se localiza na indústria de têxteis, de projeto e confecção de vestuário e de fabricação dos diversos outros elementos necessários para sua criação; assim como nos meios de comunicação de massa que propagam diversas normas do vestir, por meio de revistas especializadas, publicidade, celebridades influenciadoras etc. Entretanto, ainda dentro desse sistema os indivíduos têm um espaço de ação que lhes garante possibilidades de liberdade concernentes à escolha e ao modo de usar os artefatos de vestuário.

Diante disso, fica claro que, apesar de existirem determinadas práticas hegemônicas instituídas pelos lugares de poder, coexistem inúmeras outras práticas que sempre estão presentes na sociedade. As práticas cotidianas nem sempre são coerentes com a prática hegemônica, pois, apesar de haver uma forma "dominante" de fazer as coisas, esta não "mata” ou "apaga” as demais práticas cotidianas, elas continuam fazendo parte da realidade dos indivíduos.

Segundo Certeau (1998), quando uma prática particular que nasce da cotidianidade passa a ser usada pelo lugar de poder para organizar a vida da sociedade, não ocorre necessariamente uma alteração do lugar de poder; o que ocorre é que o lugar de poder coloniza essa prática cotidiana particular para continuar exercendo seu poder em determinado espaço. Desse modo, o que muda não é a posição de poder, e sim a tecnologia usada para exercê-lo.

Seguindo a linha de pensamento dos estudos sobre cotidiano e consumo elaborada por Certeau (1998), é possível então compreender o movimento que faz com que o vestuário nascido nas ruas, no cotidiano das pessoas e que antes não era parte do vocabulário de moda idealizado, produzido e distribuído pelos sujeitos que estão no lugar de poder dentro do sistema de moda, passe a ser usado por esse mesmo lugar de poder. É a partir das teorias a respeito do cotidiano relacionado ao consumo que estudaremos, a seguir, a maneira como a moda de rua surgida entre os jovens por volta dos anos 1960 passa a ser adotada na produção dos vestuários da Dior e em suas estratégias de divulgação na mesma época, para em seguida pensarmos quais os procedimentos fundamentais do processo desse fenômeno. Para isso, inicialmente exploraremos o papel da maison de alta-costura Dior como uma instituição que ocupa um lugar de poder dentro do sistema de moda, analisando a estética de vestuário por ela difundida; depois abordaremos o surgimento de outras práticas cotidianas relacionadas à vestimenta entre os jovens em meados de 1950 e 1960; e após isso iremos conferir a colonização das práticas de consumo de ordem tática pela marca Dior.

\section{O LUGAR DE PODER DA DIOR}

Na França, na segunda metade do século XIX, surge o primeiro estilista da história, Charles Worth, o qual instaurou um novo padrão de produção de moda que ficou conhecido como alta-costura. Nesse modelo de produção, o estilista criava roupas feitas à mão e sob medida para mulheres nobres e da alta burguesia. Os vestidos deveriam ser produções únicas e elaborados com tecidos luxuosos. Ele criou a Chambre Syndicale de la Haute Couture, que registra as maisons que podem de fato carregar o título de alta-costura, protegendo destarte as criações dos costureiros franceses, uma vez que uma peça só é reconhecida como de alta-costura se fabricada na França (DEBOM, 2011; LIPOVETSKY, 2009; MARTIN; KODA, 1995). 
Desse modo, a haute couture persistia na criação de peças que destacavam principalmente as barreiras de classe e gênero, investindo num público feminino de nível social e econômico muito alto, disposto a pagar preços exorbitantes pelas roupas (LIPOVETSKY, 2009).

Por aproximadamente cem anos, a alta-costura foi considerada a medida máxima de bom gosto para o vestuário ocidental e, por isso, atraía os olhares da imprensa e ditava as regras do vestir das mulheres em várias partes do mundo (LIPOVETSKY, 2009). Dentro do sistema de moda, a altacostura ocupava o lugar de poder, de onde produzia e distribuía novidades ligadas ao vestuário e significados a serem acessados através do consumo.

A alta-costura sofreu quando a Segunda Guerra Mundial teve início em 1939. Um dos motivos para a crise foi a escassez de matérias-primas para criação dos artefatos de moda, pois os materiais estavam sendo destinados para as necessidades da guerra. Além disso, com a ida dos homens para o campo de batalha, as mulheres passaram a ocupar cargos que antes estavam reservados apenas aos homens; muitas se tornaram operárias das indústrias, labutaram no campo ou contribuíram nos esforços de guerra, o que exigiu a produção de peças de roupa mais práticas que se ajustassem às novas atividades femininas (VEILLON, 2004).

Na época da guerra, a moda versava principalmente sobre praticidade, masculinização e despretensão, significados opostos àqueles valorizados pela alta-costura desde seu início. Isso levou ao decreto antecipado, principalmente pelo mercado de moda norte-americano, da morte dessa arte do vestuário e do fim do reinado de Paris como capital mundial da moda (BAUDOT, 1999; POLLINI, 2007; VEILLON, 2004).

Porém o fim da guerra, em setembro de 1945, trouxe consigo algumas mudanças importantes que viriam a influenciar a moda feminina da época.

No período pós-guerra, as mulheres que passaram longos anos substituindo os homens nos campos e nas fábricas, além de contribuir nos esforços de guerra, voltam para suas casas e para as posições de mães e donas de casa em tempo integral (CARDOSO, 2008).

Além disso, o período posterior à Segunda Guerra Mundial marca o florescimento do consumismo nos EUA e sua disseminação pela Europa através do Plano Marshall. Enquanto durante a guerra a austeridade era um dever nacional, o período pós-guerra contempla justamente o contrário: consumir exagerada e repetidamente se torna o dever de todos os cidadãos que querem ver a economia nacional firme. Assim, o "American way of life passou a receber uma confiança ilimitada" (adaptado de CARDOSO, 2008, p. 165).

Foi no contexto histórico do pós-guerra, marcado por um período de paz, prosperidade econômica e volta a uma feminilidade romântica, que surgiu a maison de alta-costura Dior. A maison foi inaugurada em Paris no ano de 1946 pelo estilista Christian Dior, mas seu primeiro desfile só foi realizado em fevereiro de 1947 (HANOVER, 2012).

Por surgir já como uma maison de alta-costura francesa, a Dior foi rapidamente captada pelo olhar da grande mídia e do público mundial antes mesmo de sua primeira coleção. Em novembro de 1946, por exemplo, a revista Women's Wear Daily publicou que Dior em breve abriria um negócio de alta-costura em Paris. Isso confirma a afirmação de Certeau (1998) de que na estrutura do consumo cotidiano há a preexistência de um poder que legitima o saber, pois, embora o primeiro desfile da marca não tivesse sido realizado ainda, o fato de ela estar se posicionando como uma maison de alta-costura foi suficiente para sua legitimação na sociedade. 
No primeiro desfile, a marca lançou uma linha estética chamada Corolle (fazendo referência ao formato das flores). Tal foi o deslumbre que a estética lançada por Dior causou que rapidamente a editora da versão americana da Harper's Bazaar, Carmel Snow, fez questão de rebatizá-la com o nome de New Look, que em português poderia ser traduzido como "Novo Visual" (SINCLAIR, 2012). Porém a estética não era tão nova assim. Em seu primeiro desfile, a Dior renovou um modelo de vestuário que encontra suas bases nas roupas usadas pelas cortesãs francesas do Antigo Regime (Figura 1), de maneira que a marca rompeu com a moda dos tempos da guerra ao renovar o luxo e certa feminilidade delicada, glamorosa, romântica e ociosa, por meio da valorização de ombros naturais, muitas vezes desnudos; seios elevados e em destaque; corpetes justos e muitas vezes espartilhados; cinturas marcadas; saias amplas e longas, feitas com tecidos caros e em excesso (Figura 1). Desse modo, podemos inferir que o New Look se ajustava às mudanças sociais da época, que ficou marcada pela prosperidade econômica e pela volta a um comportamento feminino mais tradicional.
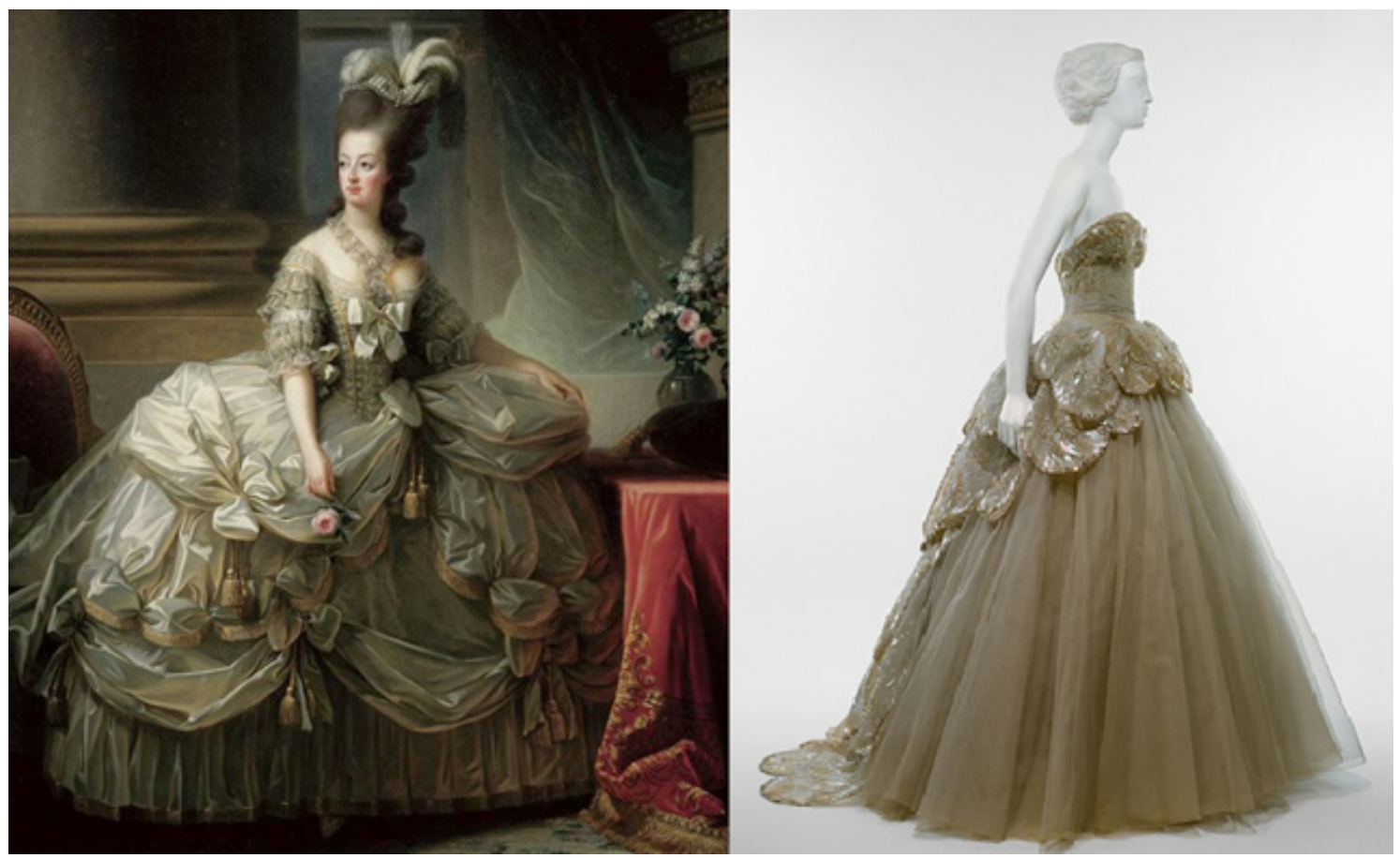

Figura 1. Imagem com fins comparativos montada com a pintura de Maria Antonieta, feita por Vigée-Lebrun em 1779, e um vestido de alta-costura da Dior criado em 1949. Fonte: Cosgrave (2005, p. 168) e Metropolitan Museum of Art².

A marca Dior ajudou a reerguer a alta-costura, pois "conhecia muito bem a história da haute couture, de modo que convocou novamente as mais finas habilidades para esse tipo de produção" (MARTIN; KODA, 1995, p. 112), além de reforçar novamente a distinção de classe e as fronteiras entre os gêneros através das roupas. Assim, a maison reafirmou Paris como capital mundial da moda, contrariando as más perspectivas dos países que queriam tomar esse posto. Suas coleções passaram a atrair a

2. Disponível em: <https://goo.gl/SpVycx>. Acesso em: 8 nov. 2015. 
atenção da imprensa global, que disseminou o New Look amplamente, fazendo com que cinturas marcadas e saias amplas fossem incorporadas, guardadas as devidas modificações, por diversas camadas sociais no Ocidente, através das mãos de donas de casa que possuíam máquinas de costura e das lojas que vendiam roupas com uma estética baseada nos lançamentos da maison (LOPES, 2014; SINCLAIR, 2012).

\section{AS TÁTICAS NO CAMPO DA MODA NA DÉCADA DE 1960}

A prosperidade econômica que se instalou nos EUA e na Europa e a paz do período do pós-guerra levaram a população a um sentimento de otimismo e segurança que resultou num fenômeno de elevada taxa de natalidade, conhecido como Baby Boom (BAUDOT, 1999; MENDES; HAYE, 2009; RAINHO, 2014).

Os baby boomers, ao atingir a juventude, estabeleceram relações sociais que exigiram novas expressões culturais capazes de manifestar o desejo por liberdade e rompimento com a cultura das gerações passadas. No campo da música, houve o nascimento do rock and roll, e ritmos como bebop e blues fizeram parte do repertório musical dos jovens da época. No cinema, novas feminilidades passaram a ser representadas, como é o caso de Brigitte Bardot, que ficou mitificada como um "sex symbol de uma feminilidade jovem emancipada e sexualmente liberada, criando um ideal de mulher moderna para a década de 1960" (BATISTA; BEZERRA, 2015, p. 17).

A moda não ficou imune às mudanças. Um estilo de vestuário surgiu entre os jovens que se distanciava daquele instituído pela alta-costura como padrão de elegância feminina.

Diferentemente da moda disseminada pela alta-costura, que valorizava a cintura marcada e saias abaixo dos joelhos, entre os jovens passou a ser usado um estilo de vestido mais solto e largo (como a forma de um A ou de tubo) e também mais curto, que deixava o corpo mais livre e exposto, materializando o desejo pelo fim da repressão do comportamento das mulheres e por uma maior liberdade sexual (BAUDOT, 1999).

O encurtamento das roupas, inclusive com o uso de minissaias, exigiu um corpo bem cuidado e atrativo, o que instituiu a magreza como ideal de beleza a ser seguido. Se antes as mulheres mais velhas tinham espartilhos para ajustar a cintura, as mais novas necessitariam manter um corpo abaixo do peso ideal se quisessem parecer com o modelo de beleza feminina. Assim, o corpo jovial passou a ser mais valorizado do que o corpo maduro. Se por um lado, antes seios e quadris eram destacados, evocando a imagem de uma mulher madura e pronta para reproduzir, agora se valorizava o corpo longilíneo e esguio, como se mesmo jovem adulta, a mulher ainda não tivesse passado pelo período da puberdade (AN INTRODUCTION..., 2017; BAUDOT, 1999; RAINHO, 2014).

Baudot (1999) e Rainho (2014) mostram que o uso de calças pelas mulheres também foi uma mudança importante na moda feminina, que forneceu maior conforto, praticidade e liberdade de movimentos, sinalizando uma mulher que cada vez se inseria no ensino superior e no mercado de trabalho, atividades reservadas aos homens, em contraste com as mulheres que antes viviam na "ociosidade" do ambiente doméstico. Além disso, a calça jeans era um objeto de uso da classe trabalhadora, uma vez que, por ser feita com material resistente, se ajustava às condições insalubres de trabalho, protegendo os sujeitos em suas respectivas atividades, principalmente nas minas e plantações. Suas 
origens não são nobres como as peças de alta-costura e sua popularização nos anos 1960 também não estava ligada ao desejo por distinção social (BAUDOT, 1999; RAINHO, 2014).

Essas novas formas de ser mulher tiveram grande influência do movimento feminista da época, pois esses anos marcaram o fortalecimento da segunda onda feminista que questionava veementemente a cultura machista e patriarcal da sociedade e buscava a liberdade pessoal das mulheres, caracterizada, dentre outras formas, pelo controle da mulher sobre seu próprio corpo e sexualidade, e por seu maior engajamento no mercado de trabalho (SNYDER, 2008). Elas não surgiram através dos desfiles de alta-costura nem das revistas de moda, pelo contrário, surgiram entre os jovens, inclusive para contestar muitos dos padrões de comportamento socialmente aceitos e impostos às mulheres, os quais eram reproduzidos pela alta-costura, cujas criações reiteravam o prestígio social das classes mais altas e uma feminilidade tradicional.

\section{A COLONIZAÇÃO DA MODA DE RUA DOS ANOS 1960 PELA MARCA DIOR}

As táticas de consumo de vestuário que os jovens criaram em seus cotidianos para fugir do que era instituído há muito tempo pela produção foram colonizadas, nas palavras de Certeau (1998), pela alta-costura, que ocupava o lugar de poder no sistema da moda, a qual as tomou como uma tecnologia de poder a ser usada para continuar escoando a produção e mantendo o crescimento das empresas e a geração de lucro.

Entretanto, uma observação minuciosa explicitará que o modo como ocorre o processo em que a prática particular de consumo surgida no cotidiano é colonizada pelo lugar de poder da produção não se configura na realização de uma cópia fiel dessa prática, pois são feitos alguns procedimentos que promovem mudanças de ordem material e imaterial. São justamente esses procedimentos que iremos observar agora, num estudo de caso acerca da forma como a marca Dior passou a criar produtos de alta-costura que dialogavam com os novos modos de vestir dos jovens nos anos 1960.

Em 1957, Dior morreu, gerando alvoroço com relação ao destino da maison, a qual, alguns pensaram, poderia afundar sem o espírito criativo de seu fundador. Yves Saint Laurent, antigo aprendiz de Dior, foi colocado em seu lugar e permaneceu no posto de estilista até 1960 (BATISTA; BEZERRA, 2015).

Laurent entrou na direção artística da empresa com o desafio de perpetuar a imagem aristocrática da Dior, porém tornando-a mais atualizada com a época contemporânea a ele. Sua primeira coleção, na primavera/verão de 1958, traduziu bem os dois conceitos ao apresentar a linha “trapézio”. Esse estilo transmitia a tradição da marca, principalmente pela matéria-prima, estrutura e modo de produção, porém tomava inspiração também na moda de rua (BATISTA; BEZERRA, 2015; BAUDOT, 1999; SINCLAIR, 2012).

A Figura 2 mostra um dos modelos da coleção Trapèze. A saia dessa peça de roupa sofreu influência do encurtamento dos vestidos e da minissaia que as jovens começaram a usar na década de 1960. As saias da Dior costumavam ser no meio da panturrilha e os vestidos chegavam a cobrir os pés, exigindo cerca de 20 metros de tecido, alguns até 80 metros (POLLINI, 2007). Entretanto, o vestido "Bonnes Vacances" tem seu comprimento diminuído, mas não a ponto de ser um minivestido como os das baby boomers, pois desce 
mais ou menos até a altura dos joelhos, enquanto os delas podiam chegar bem próximo das nádegas. Isso mostra o diálogo entre a nova estética de rua e a tradição da marca, em que foi conseguido um equilíbrio entre o curto e o longo, decidindo-se por deixá-lo na metade das pernas.

Além disso, pode-se perceber que o estilo de vestuário mais largo e solto que as jovens mulheres passaram a usar como símbolo de maior liberdade e jovialidade também influenciou o design do vestido "Bonnes Vacances”. Essa peça apresenta grande amplitude a partir dos ombros, o que lhe dá forma de trapézio, porém esse formato é conseguido justamente pelo uso do tradicional espartilho por baixo, utilizado para estruturar o tecido e fazer com que permanecesse no lugar.

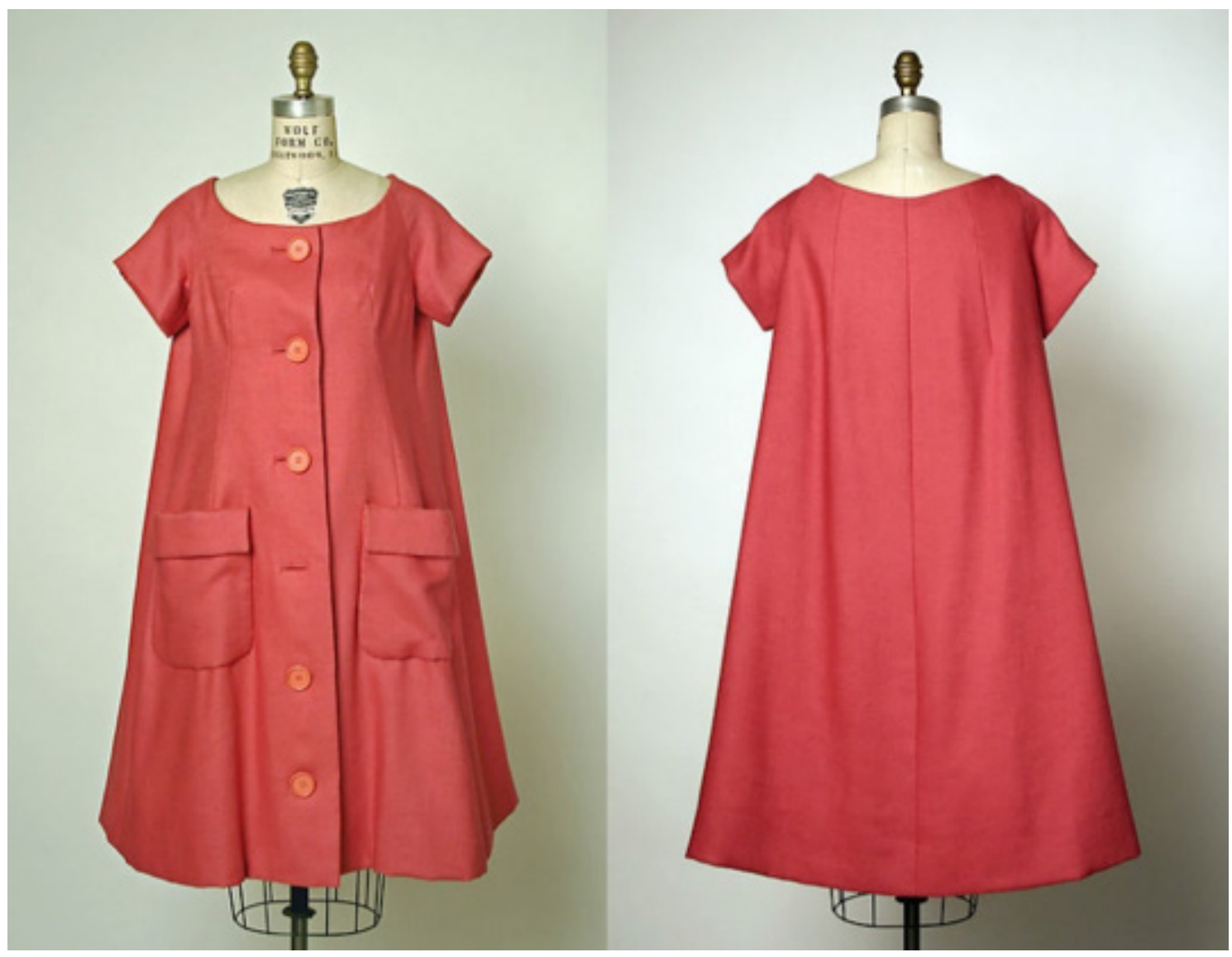

Figura 2. Vestido "Bonnes Vacances" da coleção Trapèze, 1958. Fonte: Metropolitan Museum of $\mathrm{Art}^{3}$

Na imagem a seguir (Figura 3), vemos um casaco da coleção do ano seguinte, na qual Laurent dá continuidade à linha trapézio; porém, nesse exemplar, percebe-se que a peça não possui nenhuma estrutura por baixo, ela é completamente solta e muito larga. Seu formato reitera o padrão de beleza jovem, tirando os seios de evidência e, com eles, seu sentido de maturidade. Por outro lado, seu material (lã) fazia parte do vocabulário de moda da maison Dior desde o primeiro desfile em 1947, o que reafirma certa noção de continuidade e tradição.

3. Disponível em: <https://goo.gl/XFS7sh>. Acesso em: 5 set. 2016. 


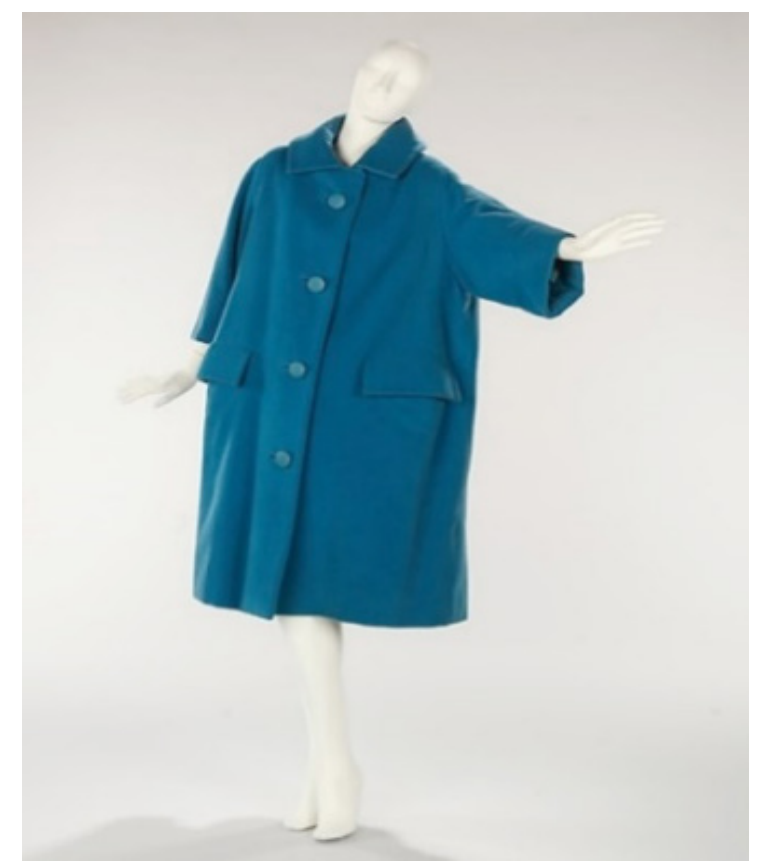

Figura 3. Casaco seguindo a linha estética Trapèze, 1959.

Fonte: Metropolitan Museum of Art ${ }^{4}$.

Apesar do sucesso inicial de Yves Saint Laurent na maison Dior, sendo inclusive reportado como o "salvador da França" pela Vogue por causa de seu primeiro desfile, ele foi bastante criticado pela coleção Beatnik de 1960, na qual lançou um casaco preto feito de couro de crocodilo (Figura 4), o qual era uma referência à perfecto jacket, vestuário que fazia parte do estilo de rua usado pelos motociclistas (SINCLAIR, 2012). Apesar de terem sido usados couro de crocodilo e pele de arminho em sua confecção, materiais caros que foram uma tentativa de dar significado nobre à peça, o look pareceu rebelde demais para o gosto das elegantes consumidoras da marca e para os sócios da empresa (BAUDOT, 1999).

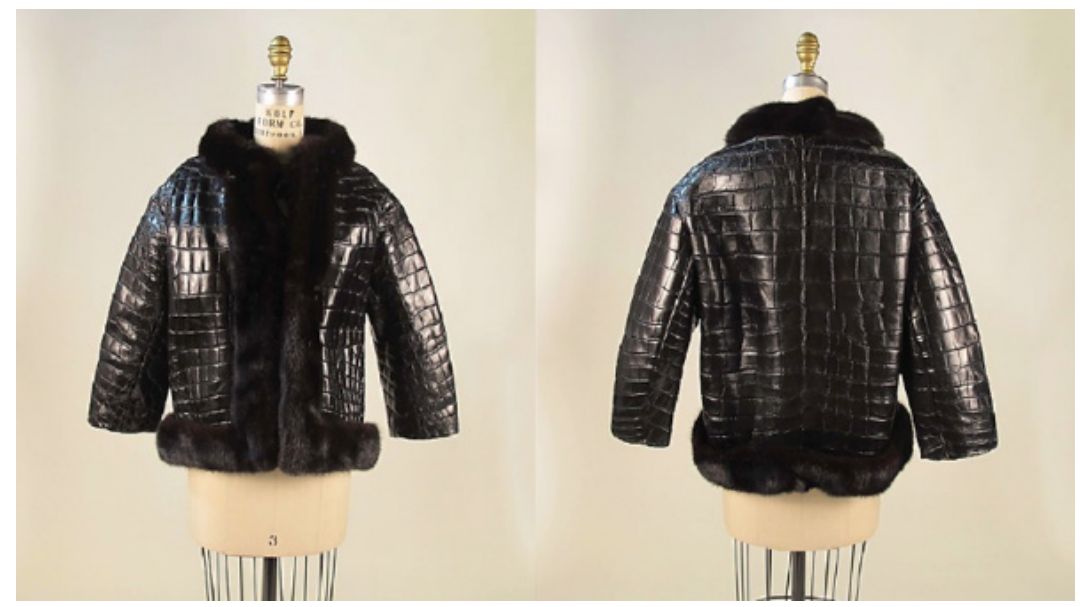

Figura 4. Jaqueta "Chicago" da coleção Beatnik, 1960. Fonte: Metropolitan Museum of Art ${ }^{5}$.

4. Disponível em: <https://goo.gl/Wz3P1u>. Acesso em: $1^{\circ}$ jun. 2016.

5. Disponível em: <https://goo.gl/QQrRVn> Acesso em: 5 set. 2016. 
Em 1961, Yves Saint Laurent deixou a marca Dior, depois de constantes conflitos com o dono da companhia. Marc Bohan, outro trabalhador da maison, tomou seu posto, permanecendo no cargo por mais de trinta anos. Ele tinha bem mais experiência que Laurent, pois trabalhava há aproximadamente 15 anos no ramo da alta-costura em maisons como as de Robert Piguet, Molyneux e Patou (BATISTA; BEZERRA, 2015).

Bohan entendia que não seria possível manter as linhas originais do New Look nos anos 1960, uma vez que progressivamente as mulheres entravam no mercado de trabalho e passavam a ter um estilo de vida mais dinâmico, onde espartilhos e saias de vários metros estariam fora de questão para o dia a dia. Entretanto, ele não podia cometer o mesmo erro que seu colega e acabar chocando suas clientes a ponto de causar repulsa e arruinar as vendas. Desse modo, Bohan tentava unir a modelagem reta e solta e os comprimentos curtos da moda de rua a outros elementos mais característicos da alta-costura, como tecidos luxuosos, fazer manual e cores claras, criando roupas mais práticas e usáveis, mas ainda assim elegantes, sofisticadas e delicadas. Desse modo, o estilista criava um diálogo entre a tradição da marca e as tendências contemporâneas dos anos 1960, década bastante marcada pelo estreitamento das barreiras de gênero (refletido nas roupas mais retas e práticas, com referências ao traje masculino) e pela valorização da jovialidade e maior liberdade sexual (mais corpo à mostra) (BETTS, 2010; BATISTA; BEZERRA, 2015).

Um exemplo do trabalho de Bohan na Dior pode ser visto na Figura 5, que mostra o conjunto “Teheran”. Seu casaco reto, referência às roupas em formato de A e de tubo das jovens, esconde por baixo uma blusa justa que evidencia a cintura estreita e cujas formas simples e saia mais curta estão aliadas a um trabalho pesado de bordados manuais sobre a luxuosa seda.

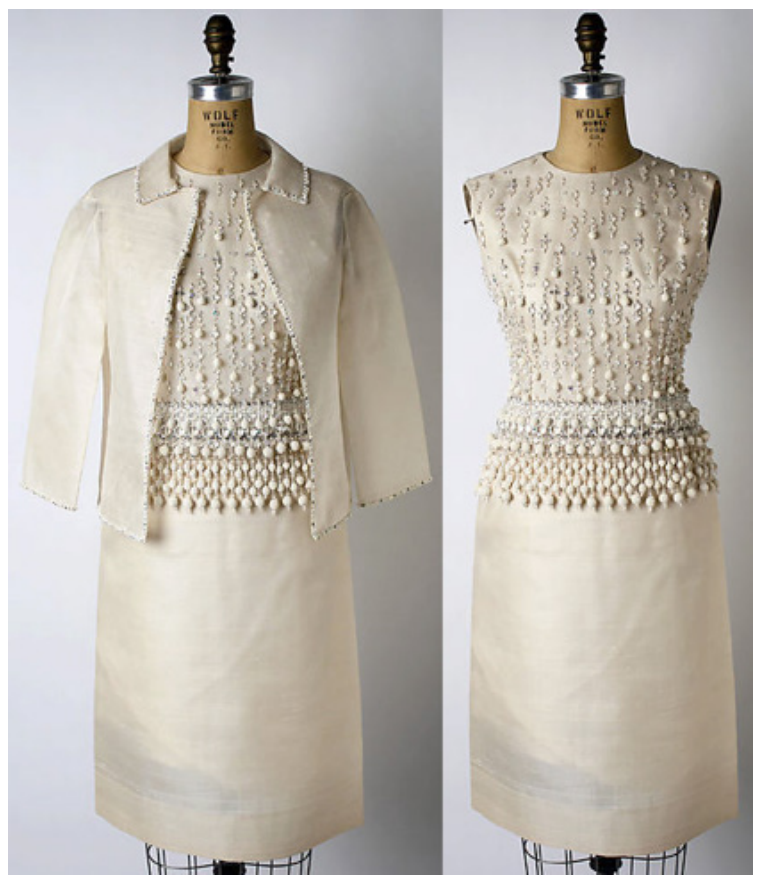

Figura 5. Conjunto "Teheran" criado por Bohan para a Dior em 1962. Fonte: Metropolitan Museum of Art'

6. Disponível em: <https://goo.gl/sm15o5>. Acesso em: 5 set. 2016. 
Uma das frases mais referenciadas de Bohan é "N'oubliez pas la femme" ("não esqueçam a mulher", tradução nossa), a qual, de acordo com Betts (2010, p. 116), foi publicada pela revista Vogue em 1964. Ela reflete o desejo de Bohan em direcionar suas clientes aos novos rumos que a moda trazia, porém, reconfortando-as ao reiterar incessantemente o ideal de mulher delicada, romântica e glamorosa - um dos símbolos mais fortes da maison Dior.

Durante a década de 1960, a Dior manteve forte ligação com o mundo cinematográfico, vestindo várias atrizes em filmes nos quais exerciam papel de protagonistas (BATISTA; BEZERRA, 2015).

Um dos filmes nos quais peças da Dior compõem o figurino da estrela principal é a produção The grass is greener (1960). Na película, a atriz Jean Simmons usou um conjunto laranja de seda da Dior, chamado L'imperatrisse chez elle (RAINHO, 2014), composto por um vestido com amarração na frente que possuía uma calça por baixo (Figura 6). Entretanto, a função prática da calça de resistir e proteger o corpo é esvaziada, pois, além de ser feita de seda, a personagem que a porta é uma ociosa aristocrata que usa esse vestuário durante uma noite que despende bebendo e festejando com colegas em uma mansão neoclássica inglesa. Seu uso está ligado à personalidade da personagem, que transgride 0 padrão de mulher romântica, pura e maternal, pois é divorciada, sem filhos, trata o sexo casual com inocência e diversão e tem atitudes infantis. Desse modo, a calça como símbolo da classe operária e como forma de proteção do corpo dá lugar ao consumo e ao ócio conspícuo das classes nobres, quando o grosso, áspero e barato jeans é substituído pela fina e caríssima seda, comunicando superioridade social e poder.

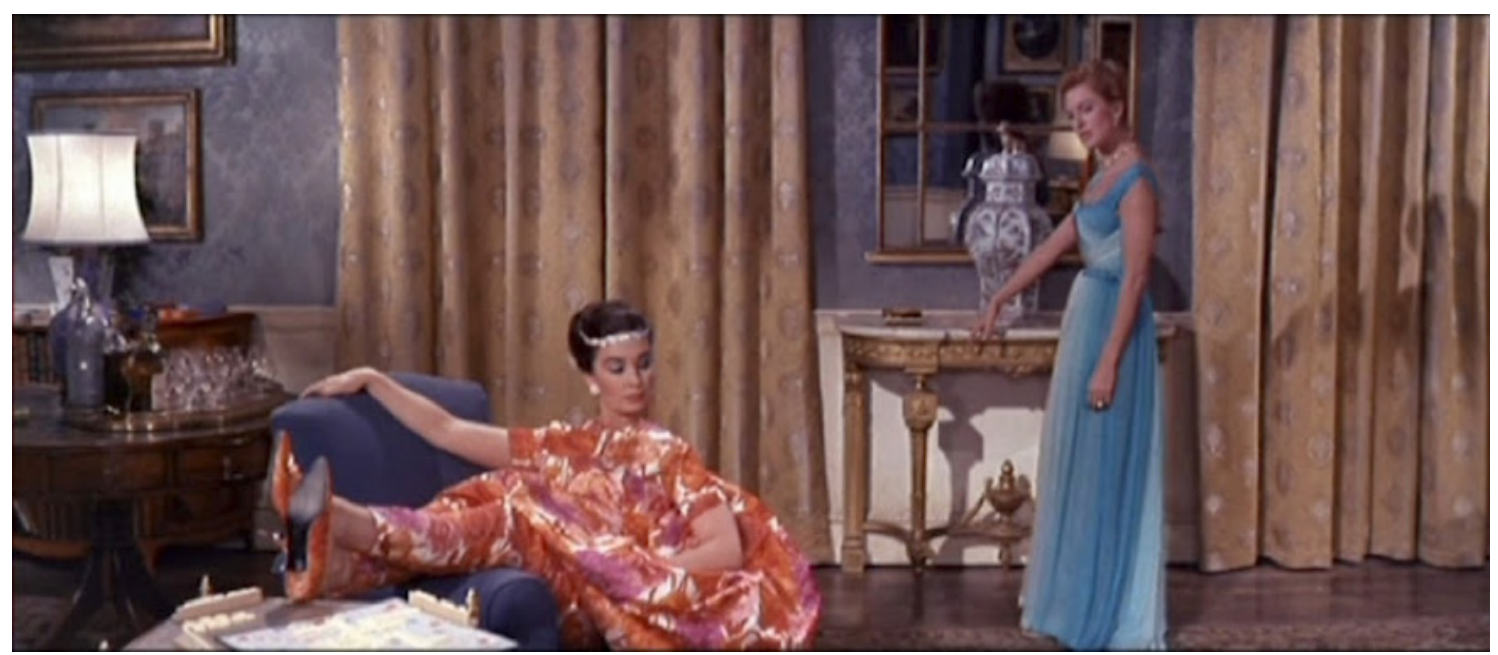

Figura 6. Jean Simmons porta o conjunto L'imperatrisse chez elle da Dior no filme The grass is greener (1960).

Fonte: Print screen de cena do filme The grass is greener (1960).

Desse modo, a estética de vestuário que antes havia sido uma tática do cotidiano das pessoas dentro do sistema de moda, um meio pelo qual muitas vezes se procurava transgredir o que era ditado pela alta-costura, é colonizada pela Dior e passa a ser disseminada para uma audiência global, impondo-se destarte como mais um padrão de beleza e estilo de vida através do endosso das celebridades. Sendo assim, a marca promove a ascensão de práticas particulares e táticas de consumo ao nível da ética, uma vez que, segundo Heller (2008), a ética serve para sujeitar a 
particularidade dos indivíduos ao humano-genérico. Quando a ética é interiorizada pelas pessoas como motivação para suas atitudes, então, ela se torna moral, a qual funciona inibindo determinados comportamentos e culturalizando o sujeito, de modo a orientá-lo e ensiná-lo a manipular as coisas para viver seu cotidiano. Ao colocar produtos que foram inspirados na moda de rua associados a determinadas celebridades, ou em determinados meios de comunicação, ou simplesmente decidir o que vai ou não ser produzido e distribuído, a Dior impõe modelos de beleza hegemônicos a serem seguidos pela sociedade no cotidiano.

\section{CONCLUSÕES}

Esta pesquisa tinha como objetivo compreender os procedimentos inerentes ao processo de colonização das práticas cotidianas de consumo pelo lugar de poder da produção. Para isso, elaboramos um estudo de caso, analisando como a maison de alta-costura Dior, que estava no lugar de poder dentro do sistema de moda, adotou o estilo de vestuário surgido entre os jovens dos anos 1960 em sua produção. Ou seja, como ela colonizou as práticas cotidianas de consumo, usando-as como tecnologias de poder.

Através da análise aqui apresentada, percebeu-se que foram empreendidos determinados procedimentos que resultaram em mudanças de ordem material e imaterial durante o processo de colonização realizado pela Dior sobre a moda de rua dos jovens.

Ao abstrair as mudanças que a Dior efetuou durante a colonização da moda de rua, encontramos quatro procedimentos essenciais que atuam no processo de colonização das práticas cotidianas de consumo pelo lugar de poder da produção:

1. Reconfiguração: houve a reelaboração da estética dos vestuários. A configuração das roupas surgidas através das táticas cotidianas sofreu modificações na forma, cor, material, estrutura e composição quando essas foram adotadas pela Dior. As formas mais largas e soltas da moda de rua, por exemplo, se uniram, nas peças da maison, a espartilhos rígidos por baixo. As minissaias inspiraram um encurtamento equilibrado dos vestidos da marca, deixando-os na altura dos joelhos, nem tão longos e nem tão curtos como entre os jovens. De forma geral, pode-se dizer que as práticas cotidianas são reconfiguradas até certo ponto. As coisas podem ser excluídas, alteradas, substituídas e/ou somadas a outras conforme o querer da produção que ocupa o lugar de poder.

2. Refuncionalização: funções foram modificadas na totalidade ou em parte nos vestuários. A calça jeans, por exemplo, teve sua função prática de resistir e proteger esvaziada, na medida em que passou a ser feita de seda, um tecido delicado. Via de regra, as funções iniciais das práticas cotidianas colonizadas podem ser alteradas até certo ponto, retiradas, trocadas por outras e/ou novas funções podem ser juntadas às já existentes.

3. Ressignificação: os significados inicialmente associados às peças de roupas surgidas entre os jovens e a classe trabalhadora sofreram intervenções. Com relação à calça jeans, empreendeu-se ações que visavam desassociá-la do sentido de inferioridade ligado à classe trabalhadora e lhe fornecer significados mais nobres, ao ser colocada para vestir uma personagem aristocrata em um filme e ser confeccionada com tecido luxuoso. De maneira geral, no processo de colonização das práticas particulares do cotidiano pelo lugar de poder, os significados 
inicialmente associados a elas podem ser excluídos; outros podem ser exagerados ou ainda eufemizados; alguns têm a possibilidade de ser reiterados; e novos significados podem ser construídos.

4. Eticalização: a partir do momento em que são colonizadas pelo lugar de poder, as práticas cotidianas se tornam o meio pelo qual o lugar de poder regula o Outro, ao submetê-lo a discursos totalizantes que poderão servir de motivação para as atitudes dos consumidores em seus cotidianos, inibindo alguns de seus comportamentos e estimulando outros. Isso ficou explícito no modo como a Dior disseminou seus produtos com inspiração na moda de rua através do endosso de estrelas cinematográficas, na tentativa de colocá-los como padrões de beleza para consumo das massas.

Como sugestão para futuras pesquisas, indicamos analisar outros casos de colonização das práticas cotidianas de consumo pela produção com base nas categorias aqui encontradas, para confirmar se elas se aplicam a contextos diferentes do vestuário e para saber a forma e o conteúdo das mudanças que resultam da aplicação estratégica dos procedimentos de reconfiguração, refuncionalização, ressignificação e eticalização em casos específicos, levando em consideração que a prática de consumo não se resume ao produto consumido mas pode comportar personagens, cenários, audiências e narrativas específicas em sua constituição. Talvez seja possível ainda estudar a maneira como os grupos sociais cujas práticas de consumo foram colonizadas resistem a tais procedimentos executados pela produção, perpetuando o diálogo entre os dois âmbitos no contexto empírico e permitindo sua discussão do ponto de vista científico.

\section{REFERÊNCIAS}

AN INTRODUCTION to 1960s fashion. Victoria and Albert Museum, London, 2017 Apr. 27. Disponivel em: <https://goo.gl/HfFt5w>. Acesso em: 15 ago. 2017.

BATISTA, I. M. S.; BEZERRA, A. A. A marca Dior no cinema (1950-1970). In: CONGRESSO DE CIÊNCIAS DA COMUNICAÇÃO NA REGIÃO NORDESTE, 18., 2016, Caruaru. Anais eletrônicos... Caruaru: Intercom, 2016. Disponível em: <https://goo.gl/PQy43M>. Acesso em: 30 nov. 2017.

BAUDOT, F. A century of fashion. New York: Thames \& Hudson, 1999.

BETTS, K. American Dior. New York: Assouline, 2010.

BATISTA, I. M. S.; BEZERRA, A. A. A narrativa da marca Dior na cinematografia das décadas de 1950 e 1960. In: ENCONTRO DE PESQUISAS EM COMUNICAÇÃO, 7., 2015, Curitiba. Anais eletrônicos... Curitiba: Universidade Federal do Paraná, 2015. Disponível em: <https://goo.gl/rVecrR>. Acesso em: 20 nov. 2017.

CARDOSO, R. Uma introdução à história do design. São Paulo: Blucher, 2008.

CERTEAU, M. A invenção do cotidiano: artes de fazer. Petrópolis: Vozes, 1998.

COSGRAVE, B. Historia de la moda: desde Egipto hasta nuestros días. Barcelona: Gustavo Gilli, 2005.

DEBOM, P. O triunfo das aparências: poder e moda no Segundo Império francês. Veredas da História, Rio de Janeiro, ano 6, n. 2, p. 185-203, jun./dez. 2011.

FEATHERSTONE, M. Cultura de consumo e pós-modernidade. São Paulo: Nobel, 1995.

HANOVER, J. Stars in Dior. New York: Rizzoli, 2012.

HELLER, A. O cotidiano e a história. São Paulo: Paz e Terra, 2008.

LEFEBVRE, H. A vida cotidiana no mundo moderno. São Paulo: Ática, 1991.

LIPOVETSKY, G. O império do efêmero: a moda e seu destino nas sociedades modernas.

São Paulo: Companhia das Letras, 2009. 
LOPES, A. C. L. F. Alta-costura, prêt-à-porter e as cópias: a difusão e produção de moda nos anos 1950. In: COLÓQUIO DE MODA, 10., 2014, Caxias do Sul. Anais eletrônicos... Caxias do Sul: Universidade de Caxias do Sul, 2014.

MACIEL, E. J. C.; MIRANDA, A. P. C. DNA da imagem de moda. In: COLÓQUIO DE MODA, 5. 2009, Rio de Janeiro. Anais eletrônicos... Rio de Janeiro: ABEPEM, 2009.

MARCONI, M.; LAKATOS, E. Fundamentos de metodologia científica. São Paulo: Atlas, 2010.

MARTIN, R.; KODA, H. Haute couture. New York: Metropolitan Museum of Art, 1995.

MENDES, V.; HAYE, A. A moda do século XX. São Paulo: Martins Fontes, 2009.

MILLER, D. Consumo como cultura material. Horizontes Antropológicos, Porto Alegre, v. 13, n. 28, p. 33-63, jul./dez. 2007.

POLLINI, D. Breve história da moda. São Paulo: Claridade, 2007.

RAINHO, M. C. T. Moda e revolução nos anos 1960. Rio de Janeiro: Contra Capa, 2014.

SILVERSTONE, R. Por que estudar a mídia? São Paulo: Loyola, 1999.

SINCLAIR, C. Vogue: Christian Dior. São Paulo: Globo, 2012.

SNYDER, C. What is third-wave feminism? A new directions essay. Signs, Boston, v. 34, n. 1, p. 175-196, 2008.

THE GRASS is greener. Direção: Stanley Donen. Produção: James H. Ware. Intérpretes: Cary Grant; Deborah Kerr; Robert Mitchum; Jean Simmons; Moray Watson; Joan Benham; Elisabeth Orionm Gwen Watford. Música: Noel Coward. Inglaterra: Universal, 1960. 1 DVD (104 min), technirama, color. Produzido por Universal Studios. Baseado na peça "The grass is greener" de Hugh Williams e Margaret Williams.

VEILLON, D. Moda e guerra: um retrato da França ocupada. Rio de Janeiro: Jorge Zahar, 2004. 